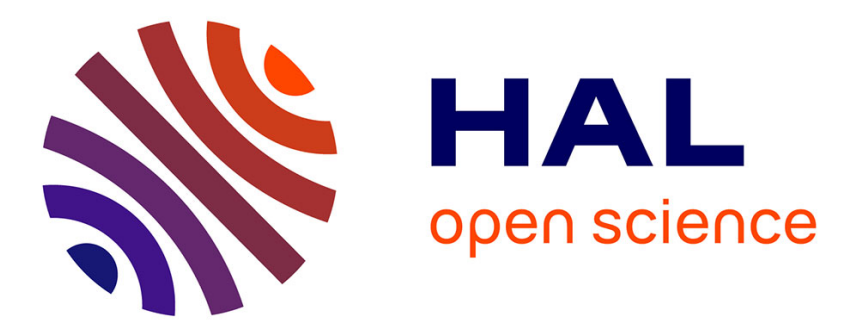

\title{
Combustion of a substitution fuel made of cardboard and polyethylene: influence of the mix characteristics -modeling
}

\author{
Sylvain Salvador, Michel Quintard, Céline David
}

\section{To cite this version:}

Sylvain Salvador, Michel Quintard, Céline David. Combustion of a substitution fuel made of cardboard and polyethylene: influence of the mix characteristics -modeling. Fire and Materials, 2008, 32 (7), p.417-444. 10.1002/fam.978 . hal-01847581

\author{
HAL Id: hal-01847581 \\ https://hal.science/hal-01847581
}

Submitted on 7 Nov 2018

HAL is a multi-disciplinary open access archive for the deposit and dissemination of scientific research documents, whether they are published or not. The documents may come from teaching and research institutions in France or abroad, or from public or private research centers.
L'archive ouverte pluridisciplinaire HAL, est destinée au dépôt et à la diffusion de documents scientifiques de niveau recherche, publiés ou non, émanant des établissements d'enseignement et de recherche français ou étrangers, des laboratoires publics ou privés. 


\title{
Combustion of a substitution fuel made of cardboard and polyethylene: Influence of the mix characteristics-Modeling
}

\author{
S. Salvador ${ }^{1, *, \dagger}$, M. Quintard ${ }^{2}$ and C. David ${ }^{1}$ \\ ${ }^{1}$ École des Mines d'Albi-Carmaux, Centre RAPSODEE, UMR 2392 CNRS Campus Jarlard, Route de Teillet, \\ 81013 Albi CT Cédex 09, France \\ ${ }^{2}$ Institut de Mécanique des Fluides de Toulouse, UMR 5502 CNRS, Allée du Pr Camille Soula, \\ 31400 Toulouse, France
}

\begin{abstract}
SUMMARY
The model proposed in this paper describes the combustion of a porous medium subjected to a radiative heat flux at its surface. There is no forced convection of air through the medium; hence this situation corresponds to the one encountered at the surface of fuel elements such as pellets, bricks or ballots, inside a furnace or kiln. Ash is not removed from the surface. No assumption is made a priori in terms of the limiting phenomena. The medium is composed of cardboard and polyethylene (PE). Based on previous experimental work (Fuel 2004; 83:451-462), the material is assumed to be a macroscopically homogeneous porous medium. Local thermal equilibrium is also assumed. Most of the parameters required for the modeling were determined from specific experiments. Good predictions of the sample mass evolution and of the temperature levels inside the sample body were obtained for a large range of densities and PE content. A devolatilization front of about $20 \mathrm{~mm}$ first propagates inside the medium. The volatile matter flux is advected to the surface, which leads to the formation of the flame above the surface. Then a second char oxidation front propagates, starting from the surface. The front thickness is approximately $25 \mathrm{~mm}$ under the experimental conditions.
\end{abstract}

KEY WORDS: combustion; porous medium; cone calorimeter; numerical model; substitution fuels

\section{INTRODUCTION}

The preparation of substitution fuels by mixing solids of very different origins is becoming a more common practice. The main interest is probably to recover energy from materials, such as plastics, that cannot be incinerated by simple feeding of industrial furnaces. As reported previously [1], simple feeding of these materials without initial compaction generates two problems: handling is

\footnotetext{
*Correspondence to: S. Salvador, École des Mines d'Albi-Carmaux, Centre RAPSODEE, UMR 2392 CNRS Campus Jarlard, Route de Teillet, 81013 Albi CT Cédex 09, France.

†E-mail: sylvain.salvador@enstimac.fr
} 
difficult and troubles such as early ignition in the feeding system may arise. For instance, plastics will melt and flow through the furnace grate. Most of the time, combustion velocity cannot be easily controlled. As a consequence, combustion produces large quantities of gas pollutants such as carbon monoxide (CO) and polyaromatic hydrocarbons (PAH). These problems can be largely solved by preparing substitution fuels. Their preparation consists of grinding selected materials and mixing and compacting them into granules, pellets, bricks or 'ballots', as required. This practice has a number of additional advantages. The substitution fuels are compacted to high densities (300-900 $\mathrm{kg} \mathrm{m}^{-3}$ typically), allowing storage in smaller volumes, eventually outdoors, while considerably limiting the risk of fire. Transport from the manufacturing site to the incinerator is also facilitated.

A particularly interesting aspect of this practice is the ability to control-through the production of the bricks - the combustion properties of the fuel. The lower calorific value (LCV) can be adjusted by mixing components with different LCV. In this manner, for instance, excessively wet materials may be mixed with drier materials. It is also possible to control the combustion velocity of the fuel. One parameter that influences this is the fuel size. Fuel density has also a direct impact on combustion velocity [1].

As reported in our previous paper [1], laboratory experiments have been carried out with substitution fuel made of cardboard and polyethylene (PE). These materials were selected as they are commonly found in wastes. In addition, the first one is characteristic of wood-derived materials and the second of plastics. A parametric study was conducted, in which three preparation variables of the bricks were varied independently. Three combustion characteristics were quantified: the combustion velocity (total mass loss rate), the temperature reached inside the bricks, and the quantities of PAH formed during the mix combustion. The three preparation variables were the size of the ground elements, the mass fractions of the two components, and the density of the compacted bricks. Combustion was achieved using a cone calorimeter (Fire Testing Technology Ltd, U.K.). The samples were of a cylindrical shape (diameter $D=100 \mathrm{~mm}$, height $H=50 \mathrm{~mm}$ ), thermally insulated on the lateral and bottom surfaces, whereas the upper face was subjected to a radiative flux of $50 \mathrm{~kW} \mathrm{~m}^{-2}$. The device was designed to obtain something close to a $1 \mathrm{D}$ configuration, as illustrated in Figure 1.

Since our objective in this paper is to bring some understanding on the experimentally observed behavior, we summarize in this paragraph the main observations; we refer the reader to [1] for

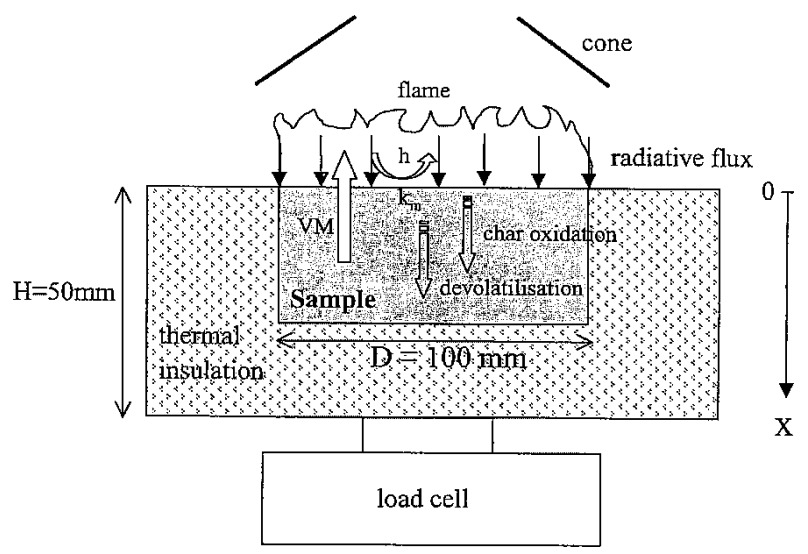

Figure 1. Experimental setup. 
a more detailed presentation. It was observed that combustion occurs in two different phases. First, a flame of burning volatile matter (VM) is formed at the surface of the sample. After this phase, oxidation of the carbon residue, or char, occurs within the sample. During the first phase, a mass loss rate of about $6.2 \times 10^{-3} \mathrm{~kg} \mathrm{~s}^{-1} \mathrm{~m}^{-2}$ relative to the area of the irradiated surface was observed, whereas the second phase induced a mass loss rate approximately 10 times smaller. Concerning the influence of the different parameters, the main conclusions of the experimental work are given as follows:

- the size of the ground components, in the range $8-40 \mathrm{~mm}$, had no significant impact on the combustion behavior of the fuels;

- the proportion of PE in the mix did not significantly affect the combustion velocity during the first phase, but it influenced the sample mass at the end of this phase. In addition, both the quantity and the nature of PAH pollutants formed during the combustion varied in very large proportions, depending on this parameter,

- surprisingly, the combustion rates $\left(\mathrm{kg} \mathrm{s}^{-1} \mathrm{~m}^{-2}\right)$ for bricks with densities in a range as large as $300-900 \mathrm{~kg} \mathrm{~m}^{-3}$ were almost the same. As a consequence, the duration of the period when a flame is formed at the sample surface was found to be proportional to the initial brick density.

The basic explanations for the two observed stages are trivial: volatilization inducing an exterior flame, followed by the progression of an internal combustion front depending on diffusion of oxygen within the sample. However, several aspects cannot be explained without a quantitative analysis. The aim of this paper is to propose a numerical model that describes correctly the combustion process. The model should allow us to identify the mechanisms that control—or limitthe combustion, along the different phases. This model, once validated by experimental results, would be used as a tool to develop new substitution fuels. To achieve this ultimate goal, the model should be able to predict the combustion velocity of substitution fuels of different dimensions, composition and density, submitted to different environments.

The model needs to describe the progress of the chemical reactions and all transport phenomena, in particular heat transfer and gas species transport. The model presented in this paper makes use of classical porous medium transport equations. As far as it was possible, the thermal properties and thermochemical properties of the materials required by the model were measured by means of specific experiments. However, some of these parameters were determined by fitting the model with the experimental results. Only combustion inside the porous medium is considered in this work. Modeling the gas-phase oxidation of the VM and the pollutants formation occurring in the flame above the brick is beyond the scope of this work.

A large number of thermal, chemical and mass transport phenomena are involved during the combustion of a solid fuel, making it very hard to understand from the simple observation of an experiment, the coupling between all the phenomena. Indeed, submitted to a radiative flux, the temperature of the fuel surface will increase. At first, heat will propagate through the porous medium by conduction and radiation. As the temperature of the solid increases, cardboard drying will occur, converting the adsorbed water into water vapor. When heated to $250^{\circ} \mathrm{C}$ for cardboard and $450^{\circ} \mathrm{C}$ for PE [1], devolatilization occurs. This will progressively convert cardboard and PE into gases, called volatile matter (VM), and leave a carbon solid residue, called char in the case of cardboard. PE is completely volatilized, whereas cardboard loses $69.1 \%$ of its initial mass during this reaction [1]. The gas pressure inside the medium will increase (i) due to expansion resulting from the heating and (ii) because of VM production. Consequently, gases 
will flow towards the medium surface: heat and mass transfer will be highly affected by advective mechanisms.

This advection mechanism may prevent oxygen from moving into the porous medium. If oxygen can diffuse- eventually counter-current to the VM flux-from the surface to the inside of the porous medium, a second type of reaction will occur: char oxidation. The products of this heterogeneous reaction between carbon and oxygen are $\mathrm{CO}$ and $\mathrm{CO}_{2}$. Only ash is left as a solid at the end of this reaction.

Modeling combustion inside a porous medium is difficult and remains largely an open problem. The literature on this topic can be divided into two groups. The first considers only combustion of the gas phase inside an inert solid porous medium. The applications that motivated research in this direction were typically porous burners. Models then appeared in which the solid phase also undergoes chemical reactions and consequently drastic textural changes. The media are called non-inert porous media. This latter case corresponds to the combustion process considered in this work.

In this type of problem, one can make a second distinction between two cases: either air is forced through the medium to feed the combustion or no forced convection occurs and oxygen supply within the material depends on the complex coupling between oxygen diffusion from the surface and the induced gas advection mechanisms. There is an important literature concerning the first case, i.e. combustion in a non-inert porous medium through which air is forced $[2,3]$. The applications are typically packed bed biomass combustion [4-7], packed bed incineration of municipal solid wastes [8-10], in situ combustion for the recovery of oil [11] or filtration combustion [12]. This situation is characterized by the presence of a combustion front that propagates through the medium. The thickness of the front is reported to be small, typically of a few particle sizes [13], less than $1 \mathrm{~cm}$ for applications of in situ combustion for the recovery of oil [11] or 5-9 times the thickness of the averaged particle size [14]. The authors refer to the high activation energies of the chemical reactions involved to explain the small front thickness. The front propagation is self-sustaining: the heat released by combustion is used to dry and devolatilize the solid phase, so that the char residue and gases that are formed can eventually be oxidized to propagate the front.

In forward combustion, air is blown co-current to the direction of the front propagation [15]. The air can also be blown in the opposite direction of the front propagation; this situation is called reverse combustion or against air flow front propagation [5; 16 in 11]. In both the cases, the structure of the front is complex, including a drying and preheating region, a pyrolysis region, a char oxidation region and a flaming region (or gas oxidation region) $[6,11]$. This results from the coupling of heat transfer, mass transfer and the several chemical reactions.

An important issue in modeling such combustion processes is the choice of the spatial scale for the description of the porous medium. In the simplest approaches, the porous medium is seen as a continuum: effective properties are used for the transport properties and for the chemical reaction kinetics in the energy and species balance equations [2,3,17]. More sophisticated approaches have been proposed and are still under development, in which the structure of the porous medium is considered at the pore scale [13,18-20]. Different approaches are then proposed either to calculate the effective values of the transport properties from the numerical simulation of an elementary cell or by volume averaging techniques in order to upscale the micro-scale equations [20,21].

Since the porous medium is described as a single mixture, the porosity of which is filled by a gas phase, the question is raised to establish whether the temperature of the two phases at a given location are close enough to assume local thermal equilibrium. Indeed, in applications where very high heat fluxes are involved, it has been shown that temperature differences of several hundreds 
$\mathrm{K}$ between the two phases exist. This was the case in the work by Puiroux et al. [21] who studied the pyrolysis of ablative composite layers and for Debenest [13] who studied different smoldering regimes in a fixed bed of solid fuel grains. Fatehi et al. [6], studying the combustion of packed beds of wood particles, found that for gas velocities lower than $0.05 \mathrm{~m} \mathrm{~s}^{-1}$, the temperature difference between the gas medium and the solid phase was negligible.

Similar questions may be raised for gas species concentrations; is there chemical nonequilibrium? The reader can refer to the work of Kaviany [18], Kaviany and Oliveira [19] or Oliveira and Kaviany [20] for a detailed discussion about this problem.

The model described below is devoted to the second class of problems, i.e. those without forced convection. In addition, we will suppose that local thermal equilibrium and local chemical equilibrium assumptions are valid.

\section{MODEL DESCRIPTION}

\section{Main model assumptions}

As indicated in the introduction, the description of the medium as an homogeneous material—or continuum-has been retained.

Mass and heat volume exchange coefficients are highly sensitive on the pore-scale characteristic length [22-24]. Nevertheless, the experiments described in our previous work [1] did not show a significant impact of the element size on the combustion process. This observation supports the choice of a local equilibrium model. Indeed, if this was not the case, changing the characteristic length of the solid elements and of the pores would have an impact on the combustion process, in terms of temperature levels and/or combustion velocity. Some effect of particle size can be observed on PAH formation, but we attribute this to mixing and reaction of gases in the flame zone above the solid sample, which is not the scope of the present work.

The combustion experiments also indicated small mass loss rates for the samples, from which it was estimated that the gas velocity inside the medium remained small. This point was later confirmed by the predictions of the model: the gas velocity remained lower than $0.015 \mathrm{~m} \mathrm{~s}^{-1}$. Given all the above arguments, a model assuming local thermal equilibrium, i.e. with a single temperature for the solid- and gas-phase mixture, was used. Concerning macroscopic mass balances, we assumed also that there is no limitation by diffusion within the gas phase for the transfer between the solid surfaces and the bulk. Consequently, the gas source term is given by the chemical reaction rate expressed in terms of the gas-phase averaged concentrations.

It was also assumed that gases do not ignite inside the porous medium. Indeed, the temperature inside the samples were measured at $1100 \mathrm{~K}$ maximum [1], which is a low value compatible with no internal flaming, as indicated by previously published works. Furthermore, as will be confirmed by the simulations, oxygen is rapidly removed from the medium during the devolatilization phase, and, therefore, the oxidation of VM becomes impossible.

The reacting porous medium is described in the model as a mix of two phases: solid and gas, the gas filling the porosity. Six different solid species are considered: cardboard and its products of thermal decomposition and oxidation, e.g. an intermediate species, carbon and ash, as described in [25], together with PE. The water absorbed inside the cardboard material is also treated as a 'solid' phase, which will be converted into water vapor (gas) during the drying process. Given the intensity of heat supply to the medium, we believe that this simple drying model is sufficient. 
Table I. Brick composition.

\begin{tabular}{|c|c|c|c|c|c|c|}
\hline & & $\begin{array}{l}\% \text { Mass of } \\
\text { cardboard }\end{array}$ & $\begin{array}{l}\text { Density, } \\
\mathrm{kg} \mathrm{m}^{-3}\end{array}$ & $\begin{array}{l}\% \text { Mass in } \\
\text { the brick }\end{array}$ & $\begin{array}{l}\text { Intrinsic } \\
\text { density, } \\
\mathrm{kg} \mathrm{m}^{-3}\end{array}$ & $\begin{array}{l}\text { Vol. } \% \text { in } \\
\text { the brick }\end{array}$ \\
\hline \multirow{6}{*}{$\begin{array}{l}\text { Cardboard, } \\
400 \mathrm{~kg} \\
\left(\rho_{\text {intr }}=1765 \mathrm{~kg} \mathrm{~m}^{-3}\right) \\
\mathrm{PE}, 100 \mathrm{~kg}\end{array}$} & Water & 7 & 28 & 5.6 & \multirow[t]{2}{*}{1000} & 2.8 \\
\hline & Vol. matters & 69.1 & 276.4 & 55.3 & & 15.66 \\
\hline & Carbon & 18.3 & 73.2 & 14.6 & \multirow{4}{*}{$\begin{array}{l}2106 \\
2000 \\
89.47\end{array}$} & 4.15 \\
\hline & Ash & 5.6 & 22.4 & 4.48 & & 1.12 \\
\hline & & & 100 & 20 & & 11.18 \\
\hline & & Total & 500 & 100 & & 34.91 \\
\hline
\end{tabular}

Theoretical initial porosity, $65.09 \%$; theoretical porosity after devolatilization, $94.7 \%$; and theoretical porosity after combustion, $98.9 \%$.

The composition of a reference brick, containing $80 \%$ cardboard and $20 \% \mathrm{PE}$, and compacted to a density of $500 \mathrm{~kg} \mathrm{~m}^{-3}$, is shown in Table I. Using the intrinsic densities of the solids, it is possible to calculate the initial volume fraction of each solid, from which the initial porosity of the brick can be calculated at $65.1 \%$.

A total of six gas species are considered. Air (nitrogen and oxygen) occupies the volume of the pores at the beginning of the experiment. Water vapor resulting from cardboard drying is an additional gas species. $\mathrm{VM}$ is a complex mix of hydrocarbons, $\mathrm{H}_{2}, \mathrm{H}_{2} \mathrm{O}$ and $\mathrm{CO}$ and $\mathrm{CO}_{2}$. Hydrocarbons range from very light species such as $\mathrm{CH}_{4}$ to heavy species such as $\mathrm{C}_{6} \mathrm{H}_{6}$. They also contain PAH-type hydrocarbons and condensable species. The VM will be represented by a single species, since it is not the focus of this paper to deal with gas-phase chemical reactions. The properties of the VM considered in the model will be those of a medium molecular weight species: $\mathrm{C}_{6} \mathrm{H}_{6}$. The species $\mathrm{CO}$ and $\mathrm{CO}_{2}$ resulting from char oxidation will also be included.

\section{Mass and energy balance equations}

Considering a 1D process, a mass balance equation is written for each of the gas species as

$$
\frac{\partial}{\partial t}\left(\varepsilon \rho_{g} Y_{g j}\right)+\frac{\partial}{\partial x}\left(\rho_{g} Y_{g j} V-\rho_{g} D_{j, \mathrm{eff}} \frac{\partial Y_{g j}}{\partial x}\right)-Q_{m, g j}=0, \quad j=1-6
$$

where the total density of the gases, $\rho_{g}$, is an intrinsic gas-phase density, i.e. expressed in $\mathrm{kg} \mathrm{m}^{-3}$ of pore volume. A full generalized Fick's law, as discussed in [26], was not used for the sake of simplicity. Calculations of the diffusion matrix for the type of composition under consideration showed extra diagonal coefficients lower than about $10 \%$ of the diagonal terms, which support the adopted representation of diffusion processes. Moreover, for the sake of simplicity, the effective diffusion coefficient will be taken in the numerical calculations as a single coefficient, as described later.

The total gas-phase mass balance equation is obtained by summing all previous equations, and one of the species balance equation may be replaced by

$$
\frac{\partial}{\partial t}\left(\varepsilon \rho_{g}\right)+\frac{\partial}{\partial x}\left(\rho_{g} V\right)=\sum_{j} Q_{m, g j}
$$


in which the Darcy velocity $V$ is given by Darcy's law

$$
V=-\frac{k}{\mu}\left(\frac{\partial P}{\partial x}-\rho_{g} g_{x}\right)
$$

The intrinsic permeability, $k$, and the gas dynamic viscosity, $\mu$, were assumed to remain constant, at values of $5 \times 10^{-12} \mathrm{~m}^{2}$ and $5 \times 10^{-6} \mathrm{~kg} \mathrm{~m}^{-1} \mathrm{~s}^{-1}$, respectively. This could be changed easily, at least for the gas viscosity, but results showed that compressibility effects are negligible under selected conditions, thus decreasing the need for a precise description of those two parameters. Moreover, since the sample is a vertical cylinder with only the upper surface opened, it can be assumed that buoyancy will not play a major role. This was checked using the developed model: setting gravity to 0 does not affect the numerical solution. The total gas density is expressed from ideal gas law

$$
\rho_{g}=\frac{P M}{R T}
$$

The energy balance equation is written under the assumption of local thermal equilibrium as

$$
\frac{\partial}{\partial t}\left(\sum_{j} \varepsilon C p_{g j} \rho_{g j}+\sum_{k} C p_{s k} \rho_{s k}\right) T+\left(\sum_{j} C p_{g j} \rho_{g j}\right) V \frac{\partial T}{\partial x}=\frac{\partial}{\partial x}\left(\lambda_{\mathrm{eff}} \frac{\partial T}{\partial x}\right)+Q_{\mathrm{c}}
$$

The mass concentration of the gas species $j, \rho_{g j}$, is an intrinsic phase value, e.g. expressed in $\mathrm{kg} \mathrm{m}^{-3}$ of pore volume. The density of the $k$-solid, $\rho_{s k}$, is related to the total volume, e.g. expressed in $\mathrm{kg} \mathrm{m}^{-3}$ of total volume (pore + solid).

The formulation of the present balance equations is similar to that proposed by $[2,3]$.

\section{Boundary conditions}

The sample bottom is impervious and adiabatic since it is placed inside a closed bottom steel cylinder with ceramic wool around. Therefore, at $x=50 \mathrm{~mm}$ we have

$$
\begin{aligned}
\frac{\partial P}{\partial x}-\rho_{g} g_{x} & =0 \\
\frac{\partial Y_{g j}}{\partial x} & =0 \\
\frac{\partial T}{\partial x} & =0
\end{aligned}
$$

The boundary conditions at the heated surface of the sample are more difficult to express. The cone calorimeter was designed for good control of the boundary conditions, essentially relying on the radiative heat flux at the sample surface $[27,28]$. The flux is calibrated at $50 \mathrm{~kW} \mathrm{~m}^{-2}$ before starting an experiment, using a cold flux meter. Nevertheless, this flux is the result of two fluxes, one resulting from the exchange between the sample surface and the heated cone and the other resulting from the exchange between the sample surface and the surroundings, that is also seen by the sample under a given view factor. The situation is even more complex due to the presence of the combustion flame. During an experiment in a cone calorimeter, the temperature of the cone 
is controlled at a constant value, about $1017 \mathrm{~K}$. Consequently, as the temperature of the sample surface increases during an experiment, the $50 \mathrm{~kW} \mathrm{~m}^{-2}$ heat flux is not maintained and cannot be adopted as a boundary condition. In order to take this effect into account, the heat flux at the sample surface is expressed as follows:

$$
q_{C, \text { surf }}=h\left(T_{\mathrm{amb}}-T_{\text {surf }}\right)+F_{1} E \sigma\left(T_{\mathrm{amb}}^{4}-T_{\text {surf }}^{4}\right)+F_{2} E \sigma\left(T_{\text {cone }}^{4}-T_{\text {surf }}^{4}\right)
$$

The convective heat transfer coefficient $h$ in the expression of the convective heat flux was estimated according to the work of Staggs et al. [27]. For a surface temperature in the range used in this work, a value of $10 \mathrm{~W} \mathrm{~m}^{-2} \mathrm{~K}^{-1}$ has been taken. The ambient temperature above the surface of the sample is fixed at a typical value of $1073 \mathrm{~K}$. Flame radiation has been neglected here. This choice is supported by the small size and the low temperature of the flame. It must be clear that Equation (9) is a crude approximation of the complex radiative and hydrodynamics conditions within the cone calorimeter. It was beyond the scope of this work to perform a complete 3D direct simulation of the entire system. It can be mentioned that a sensitivity study-that was carried out-indicated that the parameters $h, T_{\mathrm{amb}}, T_{\text {cone }}, F_{1}, F_{2}$ and $E$ all have an impact on the solution. $T_{\text {cone }}$ nevertheless remains the more influencing parameter.

The species mass fluxes at the sample surface are expressed as

$$
Q_{m s j}=k_{\mathrm{m}}\left(\rho_{g}\right)_{\text {surf }}\left(Y_{g j \mathrm{amb}}-Y_{g j, \mathrm{surf}}\right)
$$

in which the mass transfer coefficient $k_{m}$ is difficult to determine in the absence of a real modeling of the complex hydrodynamics conditions close to the surface, especially in the presence of a flame. A value of $0.012 \mathrm{~m} \mathrm{~s}^{-1}$ was estimated by running the code with different values in order to fit the experimental mass loss curves.

The condition for the pressure at $x=0$ is classically taken as

$$
P=p_{\text {atm }}
$$

\section{Initial conditions}

At time $t=0$, the porosity of the medium is filled with air. The initial pressure inside the whole sample body is equal to the atmospheric pressure $(101300 \mathrm{~Pa})$, and the initial temperature is uniform at room temperature, i.e. $20^{\circ} \mathrm{C}$.

\section{Calculation of the porosity evolution}

The solid materials of the substitution fuel when ground, mixed and compacted form a porous medium. One of the major modeling problems is that the structural properties and consequently thermal and gas transport properties of the reacting medium will change drastically during combustion. For instance, the porosity will increase from $65.1 \%$ to more than $98 \%$. The view is adopted here that all macro-scale transport parameters can be related to the porosity, whatever the history of the internal combustion processes.

The porosity $\varepsilon$ can be calculated by assuming that intrinsic solid densities do not change, i.e.

$$
\varepsilon=1-\sum_{k} \frac{\rho_{S k}}{\rho_{S \text { intr }, k}}
$$

The intrinsic densities of each solid were measured using a helium pycnometer. The results are reported in Table I. However, it was assumed that the intrinsic density of the intermediate species 
appearing during the cardboard devolatilization (see next section for a detailed description of the combustion reaction scheme) was equal to that of cardboard.

\section{Calculation of the thermal conductivity}

No direct measurement of the initial mix effective thermal conductivity was available, not to mention the mix during the combustion process. Therefore, the effective thermal conductivity of the medium was calculated based on effective medium theories, considering two limiting cases for the effective diffusion in a mixture of different phases. If the two phases were organized as parallel layers oriented in the heat flux direction, the equivalent thermal conductivity could be expressed as

$$
\lambda_{\text {paral }}=\frac{\lambda_{\mathrm{s}}}{(1-\varepsilon)+\varepsilon \lambda_{\mathrm{s}} / \lambda_{g}}
$$

and if the two phases were organized as parallel layers perpendicular to the heat flux direction, the equivalent thermal conductivity could be expressed as

$$
\lambda_{\text {ser }}=\varepsilon \lambda_{g}+(1-\varepsilon) \lambda_{\mathrm{s}}
$$

It is well known that the effective thermal conductivity of heterogeneous material is bounded by $\lambda_{\text {ser }}$ and $\lambda_{\text {paral }}$ [29], and combinations of these values will be used to estimate the effective thermal conductivity, as explained later.

First, the thermal conductivity of the PE-phase was measured at $0.22 \mathrm{~W} \mathrm{~m}^{-1} \mathrm{~K}^{-1}$, using a 'hot film' thermal conductivimeter apparatus available at our laboratory. The thermal conductivity of water was taken equal to $0.65 \mathrm{~W} \mathrm{~m}^{-1} \mathrm{~K}^{-1}$, from available data tables. It was not possible to measure the char conductivity because of handling problems. The ash conductivity, since the phase can only be collected as a powder, was not measured but fixed at a value of $4 \mathrm{Wm}^{-1} \mathrm{~K}^{-1}$. The average conductivity of the complex gas mix inside the pores is calculated as the mass weighted average of the gas species conductivities [30], i.e.

$$
\lambda_{g}=\sum_{j} Y_{g j} \lambda_{g j}
$$

The conductivity of each gas species was computed from a third-degree polynomial function of the temperature (JANAF database).

In the same manner, the average conductivity for the mix of solids is calculated as follows:

$$
\lambda_{\mathrm{s}}=\sum_{k} \frac{\rho_{s k}}{\rho_{\mathrm{s}}} \lambda_{s k}
$$

The remaining unknown, i.e. the cardboard intrinsic thermal conductivity, was obtained from the following experiment. A 'hot film' thermal conductivimeter [31] is placed between two stacks of cardboard sheets. The density of the stacks could be adjusted by a controlled compaction system. The stacks can be considered as a porous medium made of cardboard solid phase and air. The measured conductivities are reported in Figure $2(+)$ as a function of the cardboard porosity. In this figure, also plotted are conductivities $\lambda_{C \text { ser }}$ and $\lambda_{C \text { paral }}$ calculated from the models in Equations (13) and (14), with air as the gas phase and the intrinsic conductivity of the cardboard solid phase $\left(\lambda_{C \text { intr }}\right)$ taken equal to $0.6 \mathrm{~W} \mathrm{~m}^{-1} \mathrm{~K}^{-1}$. The arithmetic average of these two values, denoted by $\lambda_{B}$,

$$
\lambda_{B}=0.5\left(\lambda_{C \text { ser }}+\lambda_{C \text { paral }}\right)
$$




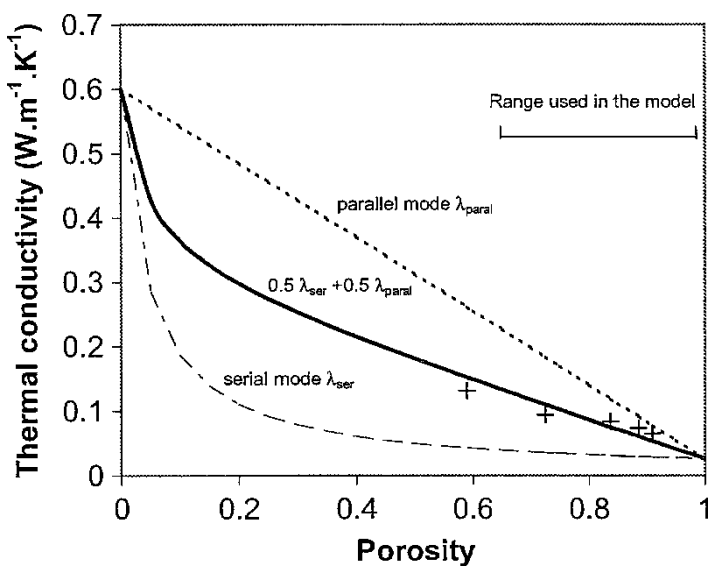

Figure 2. Effective thermal conductivity of cardboard stacks versus porosity.

is also plotted. The figure shows that the choice made for the cardboard solid-phase conductivity, together with the choice of the correlation given by Equation (17), gives a satisfactory representation of the conductivity variation with porosity, for the range of porosity relevant to this work. Therefore, a value of $0.6 \mathrm{~W} \mathrm{~m}^{-1} \mathrm{~K}^{-1}$ will be retained for the cardboard solid-phase thermal conductivity, $\lambda_{C \text { intr }}$, as well as the other correlations introduced in this development.

Radiative heat transfer is an important phenomenon that must be taken into account when modeling heat transfer in porous media at high temperature [18]. However, the associated macroscale description is particularly difficult and remains an open research problem. In the framework of this paper, radiative contribution is taken into account through the use of a polynomial expression of the temperature times the ambient temperature conductivity. This expression was established based on data concerning several refractory materials. The ambient temperature conductivity is calculated by a linear combination of $\lambda_{\text {ser }}$ and $\lambda_{\text {paral }}$. In the absence of experimental data, an expression similar to Equation (17) was chosen. Thus, the effective thermal conductivity of the medium is expressed as

$$
\lambda_{\text {eff }}=0.5\left(\lambda_{\text {ser }}+\lambda_{\text {paral }}\right)\left(3.172 \times 10^{-6} T^{2}-1.02 \times 10^{-3} T+0.992\right)
$$

\section{Heat source term}

The heat source term $Q_{c}$ is calculated from

$$
Q_{c}=\sum_{i} \frac{\partial \rho_{s i}}{\partial t} \Delta h_{i}
$$

The derivative of the density of each solid, $\partial \rho_{s i} / \partial t$, is described by the kinetic laws corresponding to the chosen reaction scheme and kinetic model. The choice of the reaction scheme and the determination of the kinetic coefficients were realized through specific experiments as described below. The reaction heats were determined during the TG/DSC (thermogravimetry/differential scanning calorimeter) tests presented in [1]. The water released was associated with an energy loss of $2.94 \mathrm{M} \mathrm{k} \mathrm{kg}^{-1}$, e.g. a reaction heat of $-2.94 \mathrm{M} \mathrm{J} \mathrm{kg}^{-1}$. The reaction heat for the devolatilization of $\mathrm{PE}$ was measured at $-1.21 \mathrm{MJ} \mathrm{kg}^{-1}$. The devolatilization of cardboard can be described using a two 
reactions scheme (see later the description of the reaction kinetics). The conversion of cardboard into the intermediate species induces a reaction heat of $-0.142 \mathrm{MJ} \mathrm{kg}^{-1}$, whereas the conversion of the intermediate species induces a reaction heat of $-0.455 \mathrm{MJ} \mathrm{kg}^{-1}$. The oxidation of the char residue is by far the more energetic reaction: the reaction heat was measured at $+35 \mathrm{MJ} \mathrm{kg}^{-1}$.

\section{Calculation of the mass source terms: chemical reactions kinetics}

The devolatilization of wood-derived materials such as cardboard is a complex process involving a large number of reactions as described in [25]. In this work, it was found that the quantities of VM and char that are formed during this devolatilization reaction depend on the thermal history to which the cardboard phase is submitted. On the basis of three experiments performed at different heating rates, and using a parameter estimation procedure, it was shown in [25] that the following simple scheme was able to describe the mass evolution of cardboard whatever the thermal history

$$
\begin{gathered}
C \stackrel{k 1}{\longrightarrow} a I 1+a^{\prime} V M \\
a I 1 \stackrel{k 2}{\longrightarrow} b \text { Char }+b^{\prime} V M
\end{gathered}
$$

where $C$ is the cardboard, $I 1$ the intermediate solid species of cardboard degradation, and $V M$ the volatile matter.

The evolution of the total mass of cardboard can be expressed as the sum of the masses of cardboard, $m_{C}$, of the intermediate species, $m_{I 1}$, of char $m_{\text {char }}$, and of ash $m_{\text {ash }}$. The derivatives are given below, except for ash that is initially present and for which the mass does not change.

$$
\begin{aligned}
\frac{\mathrm{d} m_{C}}{\mathrm{~d} t} & =-k_{1} m_{C} \\
\frac{\mathrm{d} m_{I 1}}{\mathrm{~d} t} & =a k_{1} m_{C}-a k_{2} m_{I 1} \\
\frac{\mathrm{d} m_{\mathrm{Char}}}{\mathrm{d} t} & =b k_{2} m_{I 1}
\end{aligned}
$$

with

$$
k_{i}=A_{i} \exp \left(-E_{i} / R T\right)
$$

The values for all the kinetic parameters and the values of the stoichiometric parameters $a$ and $b$ determined by the estimation procedure are grouped together in Table II. Details for the identification procedure can be found in [25].

Table II. Kinetic parameters.

\begin{tabular}{lccccc}
\hline & & \multicolumn{2}{c}{ Cardboard devolatilization } & & \\
\cline { 2 - 4 } & Drying & Reaction 1 & Reaction 2 & PE devolatilization & Char oxidation \\
\hline$A\left(\mathrm{~s}^{-1}\right)$ & $1.46 \times 10^{5}$ & $1.81 \times 10^{10}$ & 20374 & $1.05 \times 10^{17}$ & $6100 \mathrm{~kg} \mathrm{~s}^{-1} \mathrm{~m}^{-2} \mathrm{~atm}^{-1}$ \\
$E\left(\mathrm{~J} \mathrm{~mol}^{-1}\right)$ & 60133 & 125850 & 74422 & 252600 & 179400 \\
\hline
\end{tabular}

$a=0.3871$ and $b=0.3258$. 
PE thermal degradation can be satisfactorily described with a single reaction

$$
P E \longrightarrow V M
$$

and the mass source term can be expressed as

$$
\begin{aligned}
\frac{\partial \rho_{\mathrm{PE}}}{\partial t} & =-k_{\mathrm{PE}} \rho_{\mathrm{PE}} \\
k_{\mathrm{PE}} & =A_{\mathrm{PE}} \exp \left(-E_{\mathrm{PE}} / R T\right)
\end{aligned}
$$

From the TG experiments with PE, we obtained the parameters given in Table II.

In previous work [32], it has been shown that TG experiments can be used to determine the kinetic parameters for the char oxidation reaction, provided some precautions are taken. The chemical reaction considered here is the following:

$$
\mathrm{Char}+(1-f r / 2) \mathrm{O}_{2} \rightarrow f r \mathrm{CO}+(1-f r) \mathrm{CO}_{2}
$$

in which the molar fraction of $\mathrm{CO}$ in the product gases is

$$
f r=\frac{n_{\mathrm{CO}}}{n_{\mathrm{CO}}+n_{\mathrm{CO}_{2}}}
$$

The ratio $f r$ can be calculated from the Arrhenius-type expression proposed by [33]

$$
\frac{m_{\mathrm{CO}}}{m_{\mathrm{CO} 2}}=2500 \exp \left(-\frac{51843}{R T}\right)
$$

The mass evolution of the char can be calculated from

$$
\frac{\partial \rho_{\mathrm{Ch}}}{\partial t}=k_{\mathrm{Ch}} S_{\mathrm{Ch}} P_{\mathrm{O}_{2}}
$$

where $P_{\mathrm{O}_{2}}$ is the partial oxygen pressure. The intrinsic reactivity of the char $k_{\mathrm{Ch}}$ is given by a classical Arrhenius expression

$$
k_{\mathrm{Ch}}=A_{\mathrm{Ch}} \exp \left(-\frac{E_{\mathrm{Ch}}}{R T}\right)
$$

The reactive surface of the char $S_{\mathrm{Ch}}$ can be expressed from the char-specific surface $S_{\text {spec }}$ using

$$
S_{\mathrm{Ch}}=S_{\text {spec }} \rho_{\mathrm{Ch}}
$$

In the model, and for simplification, it was assumed that the specific surface remained constant along the process and equal to that of the char as measured from standard $\mathrm{N}_{2}$ BET test, i.e. $8690 \mathrm{~m}^{2} \mathrm{~kg}^{-1}$ (measurement made at our laboratory).

The gas species source terms $Q_{m, g j}$ were calculated using the derivatives of the solid masses and using the stoichiometric factors in the chemical reactions.

Drying is a complex process. In the proposed model, a simplified description is used, which allows the main features of the problem to be maintained, as far as heat balance is concerned, namely the mass and energy source terms. The kinetic law is here simplified to an Arrhenius-type equation, as previously done in $[34,35]$, and the adopted kinetic parameters are given in Table II:

$$
\text { Water(liquid) } \rightarrow \text { Water(gas) }
$$


with

$$
\frac{\partial \rho_{w}}{\partial t}=-k_{w} \rho_{w}
$$

and

$$
k_{w}=A_{w} \exp \left(-\frac{E_{w}}{R T}\right)
$$

Gas diffusivity

The effective diffusivity inside the porous medium for all the gases was calculated as follows:

$$
D_{\text {eff }}=D_{g} \frac{\varepsilon}{\tau}
$$

in which the gas diffusivity $D_{g}$ depends on the local temperature according to

$$
D_{g}=1.7 \times 10^{-5}\left(\frac{T}{273}\right)^{3 / 2}
$$

As indicated earlier in this paper, a generalized Fick's law with a complete description of all diffusion terms was not considered [26]. Given the amount of uncertainty in the determination of effective diffusivities, that problem was ignored. However, this is not a limitation in the numerical model, and effective diffusion coefficients could be used.

The medium tortuosity, $\tau$, is difficult to measure directly for these materials. Its value is likely to change during the combustion process because of the solid-phase evolution. It was assumed in this work that the value remained constant at $\tau=2$. This is not of course a numerical limitation, but rather a problem of experiment interpretation.

\section{NUMERICAL SCHEME}

Numerical modeling of multicomponent transport with chemical reactions in porous media has received much attention [36-38]. This work does not offer any new original perspective on this subject; therefore, presentation of the numerical scheme will be kept to a minimum since the choices made were very classical. First, a volume element description was adopted based on a grid of fixed mesh size. Resulting fluxes expression were discretized using classical finite difference formulae, for instance, velocity at the interface of the control volume corresponding to node $i$, is expressed as

$$
v_{i+1 / 2}=\left(-\frac{k}{\mu}\right)_{i+1 / 2}\left(\frac{P_{i+1}^{n+1}-P_{i}^{n+1}}{\delta x}\right)
$$

Transport parameters at a position such as $i+1 / 2$ or $i-1 / 2$ were estimated by harmonic averages as described in [39]. It was verified a posteriori that the cell Peclet number $P e_{\mathrm{c}}$ defined by

$$
P e_{\mathrm{c}}=\frac{v \delta x}{D_{\text {eff }}}
$$


remained small, lower than 1 . Therefore, for simplicity, an upstream scheme was adopted to handle advective terms. All equations were treated in an implicit manner. The way the set of equations has been handled is based on a sequential approach, which proved to be sufficient for our diffusioncontrolled problem. Indeed, many possibilities were available as discussed in $[36,38,40]$. This sequential approach firstly solves a pressure equation obtained by combining Darcy's law and the gas-phase total mass balance equation. Other equations are solved sequentially, starting with the solid decomposition equations. The resulting linear systems were solved by classical iterative methods. Typical choices for the numerical parameters were: about a hundred nodes and time step of about $0.1 \mathrm{~s}$. This latter parameter was largely determined by the physical characteristic times involved in the combustion process. No adaptive time steps were used, while the results below may suggest it could be interesting to implement such algorithms to handle the different process characteristic times.

\section{RESULTS AND INTERPRETATION}

\section{Comparison of the model predictions with experimental results}

As discussed in the Model Description section, several parameters required by the model could not be measured. This is the case for thermal conductivity of the char and for tortuosity of the porous medium, which are important in the combustion process as it will be demonstrated later. The values chosen in the previous section were determined by comparison of the model with the experimental results presented in previous work [1]. The reference case is described in Figure 3. In this figure, the predicted total mass evolution of the sample is plotted versus time, and comparison with the results in Figure 4 shows that the two-step evolution observed experimentally is preserved by the model. The first high mass loss rate period will be termed the devolatilization phase, and the subsequent low mass loss rate period the char oxidation phase. Figure 3 also shows that increasing the thermal conductivity of the char $\lambda_{\mathrm{Ch}}$ from 30 to $40 \mathrm{~W} \mathrm{~m}^{-1} \mathrm{~K}^{-1}$ results in an acceleration of the devolatilization process, whereas increasing the tortuosity of the porous medium $\tau$ from 2 to 3

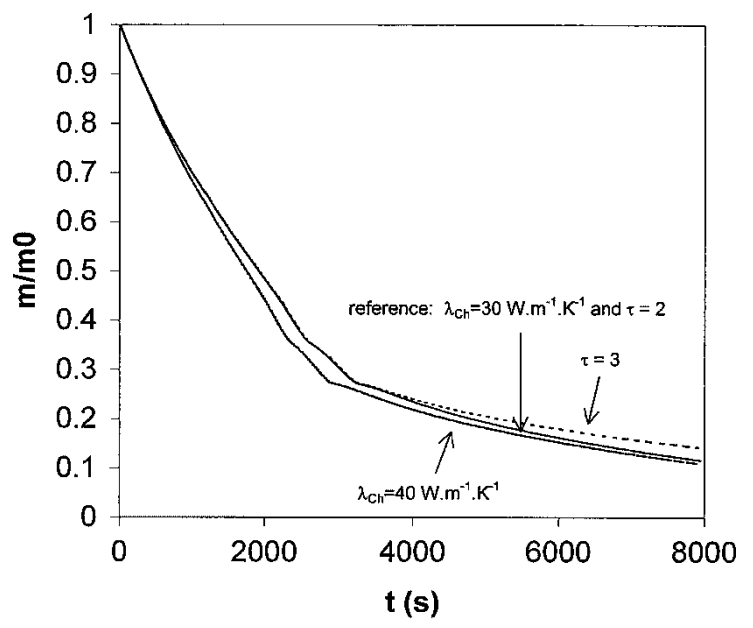

Figure 3. Sensitivity of the model to tortuosity and carbon thermal conductivity. 


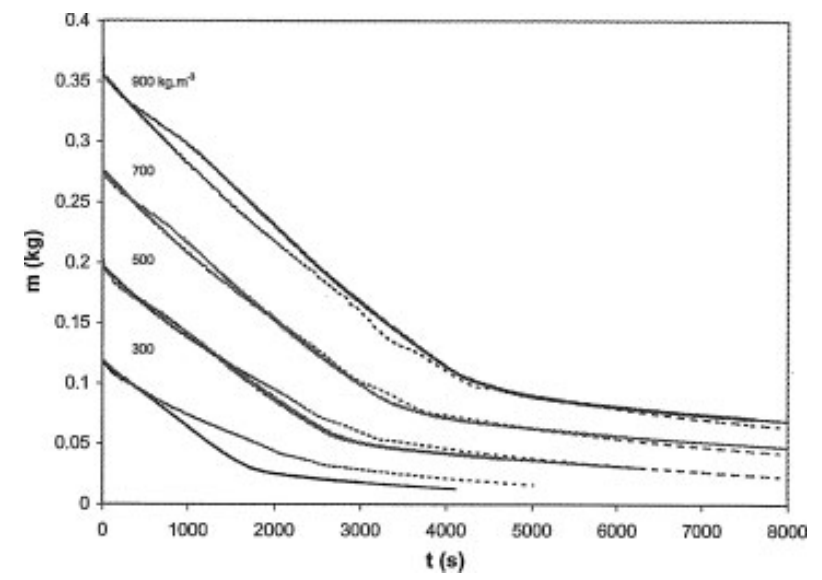

Figure 4. Total mass evolution versus time for the different brick densities: (-) experiments; (- - -) model.

decreases the mass loss rate during the char oxidation phase only. Therefore, it was possible to fit these two parameters independently, using all the sets of experimental data at our disposal: as indicated earlier, the best fit was obtained with $\lambda_{\mathrm{Ch}}=30 \mathrm{~W} \mathrm{~m}^{-1} \mathrm{~K}^{-1}$ and $\tau=2$.

The predictions of the model using these two values are given and compared with the experimental results in Figures 4 and 5. For the cases of the samples at 500,700 and $900 \mathrm{~kg} \mathrm{~m}^{-3}$ initial density, the model predictions in Figure 4 are in good agreement with the experimental results. The prediction for the lower density sample, at $300 \mathrm{~kg} \mathrm{~m}^{-3}$, is less satisfactory. However, the model does preserve the experimentally observed fact that the devolatilization phase duration, corresponding to the presence of a flame at the sample surface, is proportional to the initial sample density [1].

Figure 5, where the evolution of the total mass of various samples with different percentages of $\mathrm{PE}$ is plotted, indicates that the model predicts satisfactorily the impact of the composition of the fuel on the combustion process. The higher the percentage of PE, the longer the devolatilization phase and the lower the sample mass at the end of this phase. The results for the sample at $70 \%$ PE, where the model predictions do not fit the experiment, can be explained from the observation of the experiments reported in [1]. Indeed, when the percentage of PE is too high, the structure of the porous medium is not conserved through the combustion process: the surface of the sample does not remain planar, and flow of melted PE is observed. The model cannot be used to describe this particular (and not industrially interesting) situation.

The predictions of the model in terms of the temperature reached inside the sample are given in Figure 6(a) and (b), for the cases of samples with initial densities of 500 and $900 \mathrm{~kg} \mathrm{~m}^{-3}$, respectively. The temperature was measured using three refractory steel protected thermocouples placed $5 \mathrm{~mm}$ below the surface $(x=5 \mathrm{~mm})$, in the middle of the sample $(x=25 \mathrm{~mm})$ and $5 \mathrm{~mm}$ from the bottom of the sample $(x=45 \mathrm{~mm})$ [1]. The agreement between predictions and actual data is globally satisfactory. The results can nevertheless sometimes be different by more than $100 \mathrm{~K}$. These differences can be attributed, in our opinion, to the difficulty in measuring the temperature inside this reacting and changing medium at high temperature. In particular, the thermocouple placed $5 \mathrm{~mm}$ below the surface of the sample is not mechanically well maintained: as the sample is devolatilized and oxidized, the medium mechanical strength becomes very small. It was observed that the thermocouple sometimes moved away from its initial position, sometimes 

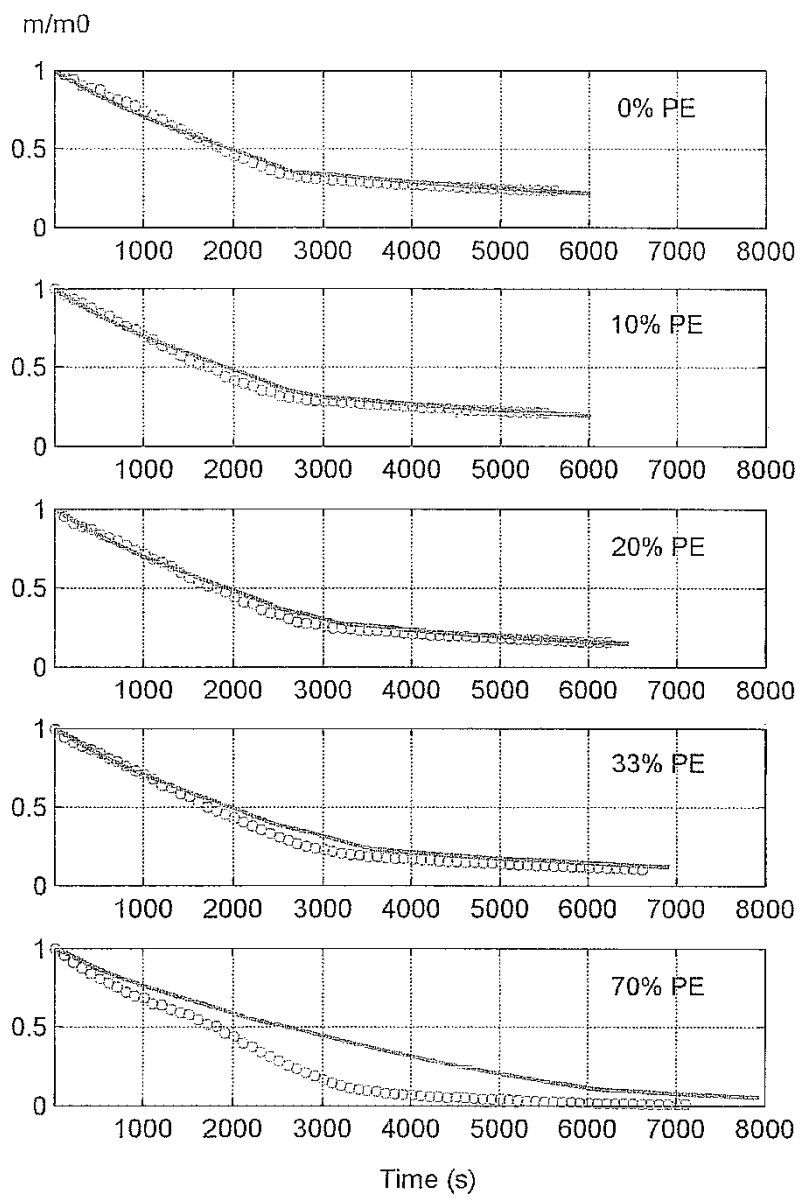

Figure 5. Influence of the initial PE content on the mass evolution curves: (ooo) experiments; (-) model.

pointing above the surface of the sample, which may explain the large deviations in the temperature measurements.

Analysis of the combustion process from the model results

The above results offer a reasonable validation of the proposed combustion model for PE-cardboard mix. It is now possible to use this model to better understand the mechanisms occurring during an experiment for a given brick. In this section, analysis is made of the results from the model in the case of the reference brick, e.g. at a density of $500 \mathrm{~kg} \mathrm{~m}^{-3}$, and containing $20 \%$ of PE. Let us remember that the size of the ground elements entering the brick composition has been shown [1] to have no impact on the combustion process and is not considered directly in the model. At this point, it is necessary to propose an explanation of this phenomenon. The pore size appears in the macro-scale equations through the value of different effective parameters. In our model, the main influence is expected on the permeability (tortuosity does not depend on the pore size, for a similar geometry). Permeability determines the pressure level in the brick. The building up of pressure is essentially associated with the velocity field, which is itself mainly induced by the source term 

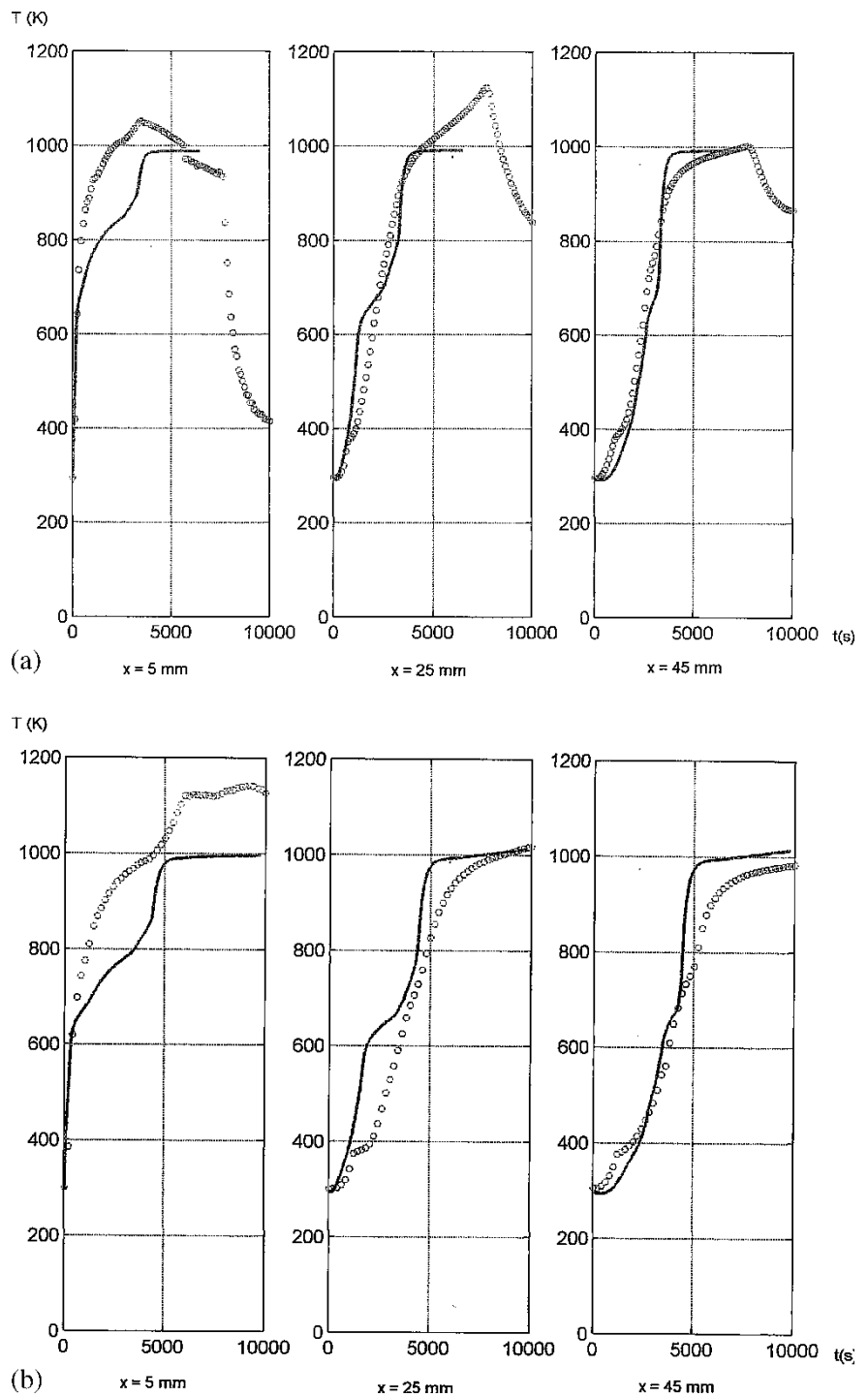

Figure 6. Temperature evolution at three locations within the sample for a brick density of (a) $500 \mathrm{~kg} \mathrm{~m}^{-3}$ and (b) $900 \mathrm{~kg} \mathrm{~m}^{-3}$ : (ooo) experiments; (一) model.

in the gas mass balance equations, and this term is pressure independent. The maximum pressure observed during the simulation depends on the maximum velocity and the permeability. In all our numerical calculations, it was found to be less than $0.3 \%$ of the imposed pressure. Therefore, the pressure build-up has little influence on the other pressure-dependent parameters, which explains why the pore size has no influence on the combustion process. To obtain an influence of the pore size, permeability should be decreased by more than one order of magnitude. In passing, this discussion illustrates the interest of physical and numerical modeling for these combustion processes, since pressure is difficult to measure in such conditions. 


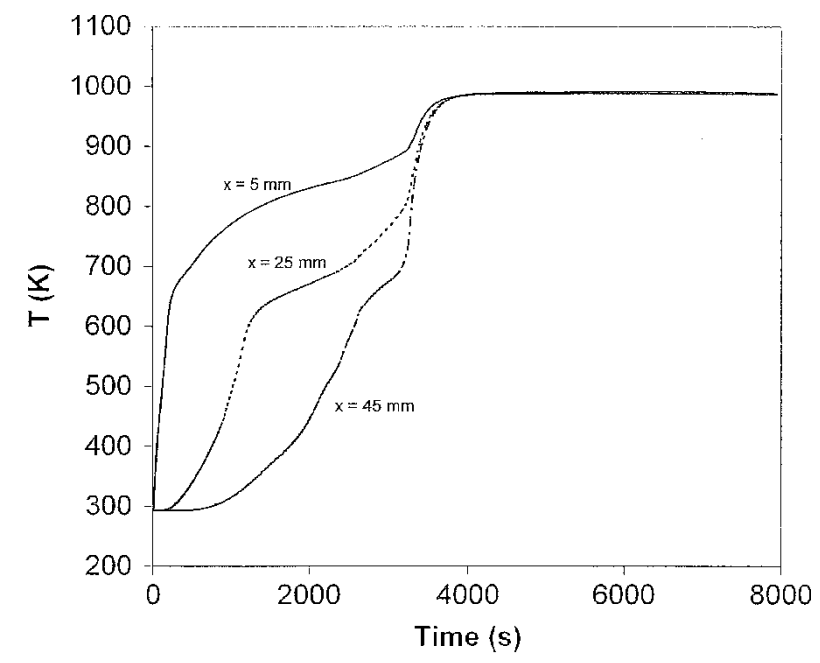

Figure 7. Comparison of the numerical temperature evolution at three locations within the sample for a brick density of $500 \mathrm{~kg} \mathrm{~m}^{-3}$.

Because of mechanical stability reasons, all the experiments had to be stopped after a duration of about two times the duration of the devolatilization phase. As a consequence, the results are reported up to this time only.

\section{TEMPERATURE EVOLUTION}

The time evolution of the temperature inside the samples at 5,25 and $45 \mathrm{~mm}$ below the irradiated surface is plotted in Figure 7. The top of the sample is heated rapidly and the temperature inside the sample is not uniform. The temperature increase, for the nodes at the center and at the bottom of the sample, is delayed by several hundreds of seconds. The temperature curves feature different plateaus. First, the drying process, occurring at temperatures close to $373 \mathrm{~K}$, induces a very weak plateau, only visible for the node close to the sample bottom. The plateau between 600 and $750 \mathrm{~K}$ can be attributed to the endothermic devolatilization reactions for cardboard and PE, as indicated by the thermal behavior of these products during the TG experiments [1]. At about $3000 \mathrm{~s}$, the temperature of the node next to the surface seems to stay constant at a value close to $900 \mathrm{~K}$, until the bottom node temperature reaches the same value. This stagnation of the surface temperature is certainly due to the convective flux of the cooler VM generated inside the brick. The temperature inside the brick rapidly increases and becomes uniform at approximately $1000 \mathrm{~K}$. It should be noted that even after $8000 \mathrm{~s}$, the combustion process is not complete, as can be seen in Figure 4 where the total mass of the sample is still decreasing.

\section{POROSITY EVOLUTION}

Figure 8 provides a better understanding of the internal processes occurring during the brick combustion. This figure represents the time evolution of the porosity at the surface, middle and 


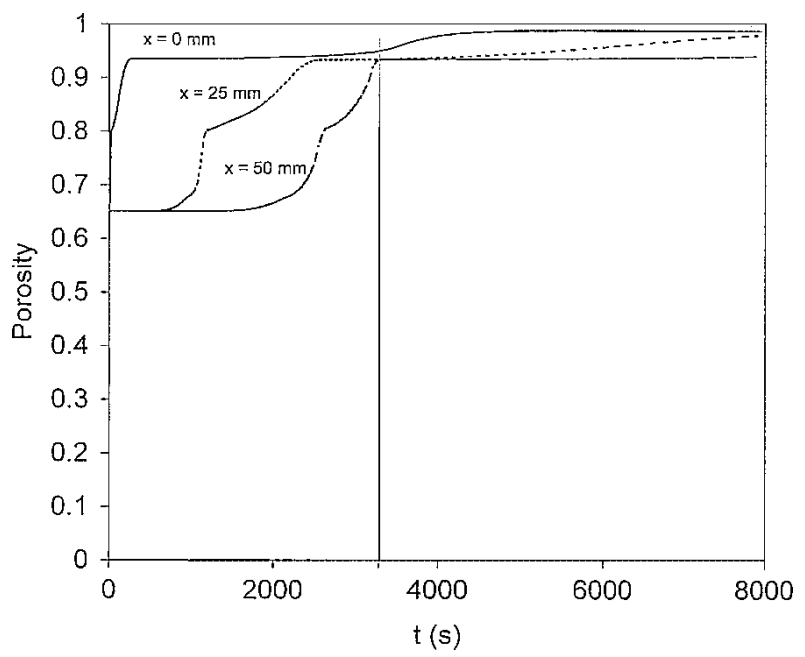

Figure 8. Porosity evolution at three locations within the sample for a brick density of $500 \mathrm{~kg} \mathrm{~m}^{-3}$.

bottom of the sample. Again, the results show four different stages. First, porosity increases from its initial value of $0.65-0.68$, and a very weak plateau is observed, corresponding to the drying mechanism. Then, porosity increases to a value of 0.8 , and this may be related to cardboard devolatilization. During the third stage, porosity increases up to 0.94 , and this can be attributed to PE devolatilization. Then, porosity at the surface and center nodes remains constant at the value of 0.94 , until the bottom node reaches the same value, at $t=3150 \mathrm{~s}$. It should be noted that, at this time, the sample porosity is uniform inside the brick and close to the char + ash theoretical porosity of $94.7 \%$. At this stage, the brick is fully devolatilized, and the char is not oxidized. After this, the surface porosity increases up to 0.98 , due to char oxidation, which eventually leaves only ash as a solid residue. The oxidation at the center node will take more than $8000 \mathrm{~s}$, whereas the node at the bottom still has not oxidized at this time. It is likely that the oxidation of the surface node has not started before the bottom node is fully devolatilized because of the temperature 'blocking' and because the VM convective flux has also prevented $\mathrm{O}_{2}$ from diffusing inside the brick. This separation between the two major processes, i.e. devolatilization and oxidation, will be confirmed later.

\section{GAS VELOCITY EVOLUTION}

In Figure 9, the time evolution of gas velocity inside the porous medium is shown for three locations, as in Figure 8. The model predicts the establishment within a few seconds of a velocity of $-0.015 \mathrm{~m} \mathrm{~s}^{-1}$ at the sample surface. This is in agreement with the experiments, during which a flame was observed at the surface several seconds after applying the radiative flux $(t=0)$. The velocity decreases slowly to $-0.0125 \mathrm{~m} \mathrm{~s}^{-1}$ at $2000 \mathrm{~s}$, and then goes through two peak values before suddenly falling almost to zero. This can be compared with experimental observations, which gave similar semi-quantitative results. The flame was systematically intense-200 $\mathrm{mm}$ high—and orange at the beginning. Then, a slow decrease in intensity over a long period was observed, followed by a clear increase in intensity before sudden extinction. After this, a very weak (several 


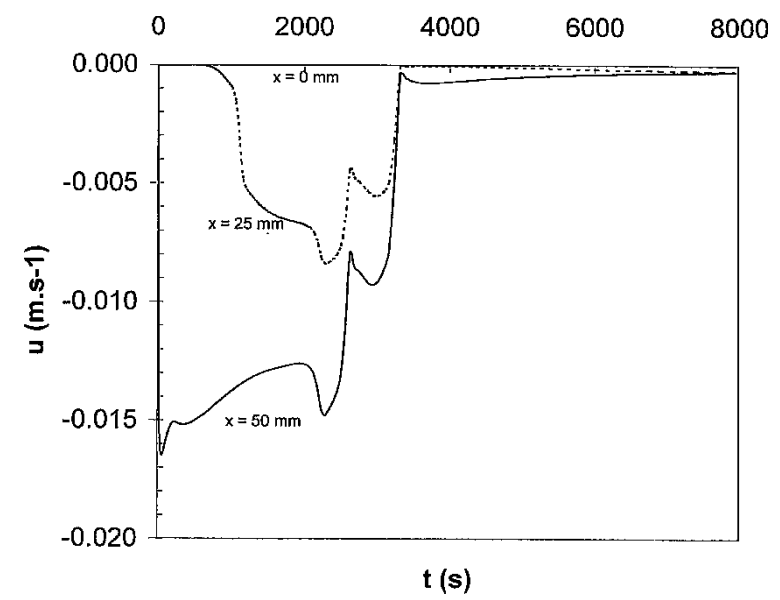

Figure 9. Gas-phase velocity evolution at three locations within the sample for a brick density of $500 \mathrm{~kg} \mathrm{~m}^{-3}$.

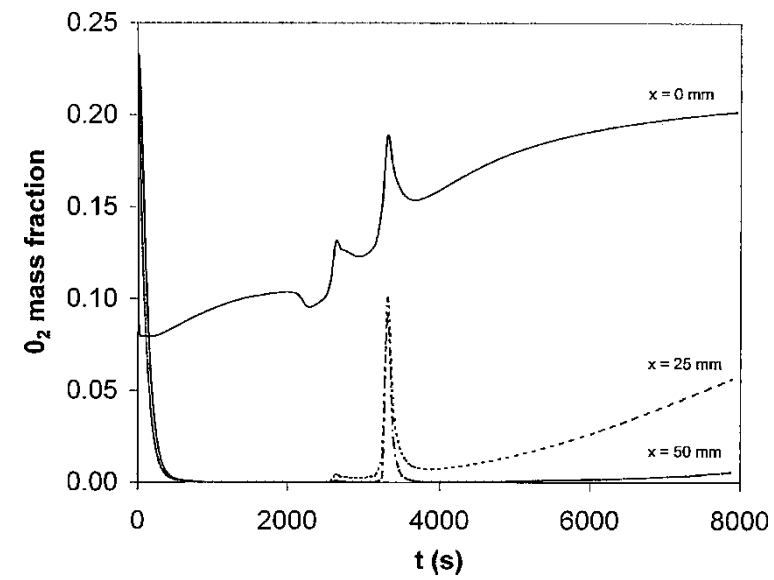

Figure 10. Oxygen mass fraction evolution at three locations within the sample for a brick density of $500 \mathrm{~kg} \mathrm{~m}^{-3}$.

mm thick) blue flame was observed moving at the sample surface. The model predicts that a small gas velocity is maintained at the surface of the sample after the devolatilization phase and that the gas contains approximately $8 \% \mathrm{CO}$. This can explain the presence of the thin blue flame observed during the beginning of the char oxidation phase (Figure 10).

\section{PRESSURE EVOLUTION}

Concerning the pressure field, the model predicts that the pressure never exceeds $400 \mathrm{~Pa}$ relative to the imposed pressure. It should be noted that this value overestimates the actual pressure, since permeability is supposed to remain at its initial value, whereas it is likely to change as the porosity of the medium largely increases. This confirms that the overpressure is not significant and that 
compressibility phenomena can be neglected in this problem. It can be concluded also that the assumptions of constant permeability and constant gas viscosity do not introduce significant errors in the model solution. However, we remind the reader that combustion of media with much lower initial permeability may change these conclusions.

\section{MASS FRACTION EVOLUTION}

Examination of the $\mathrm{O}_{2}$ mass fraction inside the brick is of particular interest. The results are given in Figure 10 as the time evolution at three locations. At the sample surface, the $\mathrm{O}_{2}$ fraction falls from 0.23 (in air) to 0.08 within a few seconds. It then increases slowly along the combustion process but has not reached the 0.23 air composition by $8000 \mathrm{~s}$. For the nodes in the middle and at the bottom of the brick, the decrease in $\mathrm{O}_{2}$ fraction is slower, but the values fall to virtually 0 after about $500 \mathrm{~s}$. There is no oxygen inside the brick during the devolatilization phase. This explains why oxidation of the char cannot occur during this first phase. This process can be explained by the fact that diffusion is not strong enough to bring oxygen to the sample bottom, while the gas production induces a velocity field that drives oxygen from the brick. The ratio of oxygen diffusion to advection fluxes can be estimated as

$$
\left\|\rho_{g} D_{\text {eff }} \frac{\partial Y_{g j}}{\partial x} / v \rho_{g} Y_{g j}\right\| \approx \frac{3.510^{-5}(0.23-0.00)}{0.005 \times(0.23 / 2) \times 0.05} \approx 0.28
$$

where the velocity has been estimated from the numerical results (see Figure 9), the maximum change in mass fraction has been taken to be 0.23 , the sample size being $0.05 \mathrm{~m}$. It can be seen that the advective flux is much greater than the diffusion flux, thus preventing oxygen from penetrating into the sample. At $t=3150 \mathrm{~s}$, which corresponds to the end of devolatilization and VM emissions, the oxygen fraction suddenly increases inside the entire brick. Indeed, velocity becomes zero, and diffusion can bring oxygen into the sample. It must be emphasized that the characteristic diffusion time for the sample is about

$$
\frac{D^{2}}{D_{g} / \tau} \approx 0.05^{2} /\left(0.5 \times 1.710^{-5} \times(T / 273)^{2 / 3}\right) \approx 72
$$

if a value of $T \approx 700 \mathrm{~K}$ is taken. This is relatively short compared with the other characteristic times observed in the process. It is obvious that the oxidation of char starts at this time, when oxygen comes into the porous medium, causing the rapid increase in the temperature observed previously in Figure 7. Because of the oxidation reaction consuming $\mathrm{O}_{2}$, its mass fraction decreases again rapidly. Then the oxidation process progresses slowly due to the low $\mathrm{O}_{2}$ fraction that is established. Indeed, less than $1 \% \mathrm{O}_{2}$ is present at the bottom of the brick. The diffusion coefficient is not large enough to compensate for the oxygen consumption. In conclusion, it is seen that the combustion process is mainly controlled by oxygen diffusion within the sample.

The results plotted in Figure 11 will allow us to clarify the existence of internal combustion fronts. This figure represents the temperature and porosity profiles along the brick, at time $t=1000 \mathrm{~s}$, which is about half the time needed for full devolatilization of the brick. We observe very important temperature gradients inside the brick for this time. Nevertheless, the observation of the porosity profile clearly shows two regions where the porosity is uniform. Between $x=30$ and $50 \mathrm{~mm}$, the initial porosity of 0.63 , e.g. that of the initial mix, is conserved, and, between the surface and 


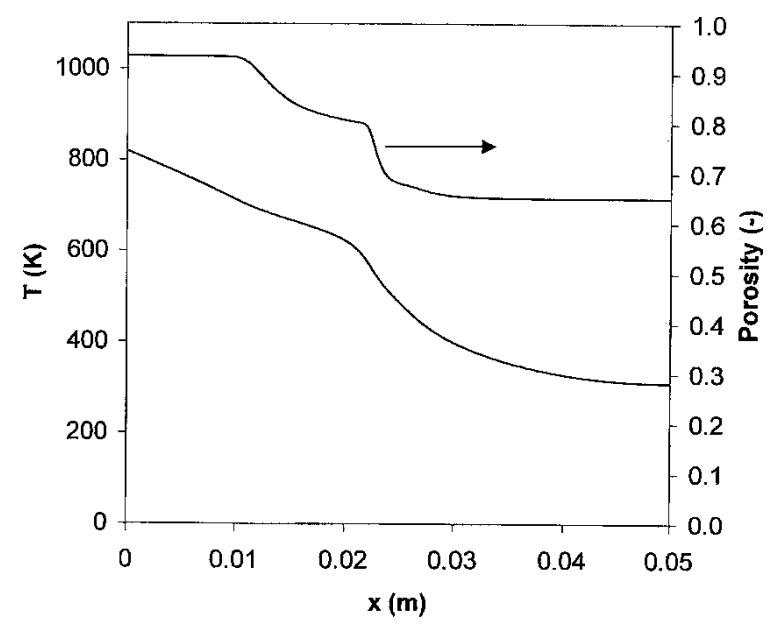

Figure 11. Temperature and porosity fields at $t=1000 \mathrm{~s}$ (devolatilization phase).

$x=10 \mathrm{~mm}$, the porosity is 0.94 , corresponding to the 'char+ash' porosity. In between these two regions, a devolatilization front is clearly identified. This front can be divided into a first small step change at $x=25 \mathrm{~mm}$, corresponding to the drying front. The step change at $x=23 \mathrm{~mm}$ is due to cardboard devolatilization, whereas the front around $x=12 \mathrm{~mm}$ is due to PE devolatilization. The total thickness of the front is approximately $20 \mathrm{~mm}$. These interpretations are confirmed by the results in Figure 12, in which the profiles of the masses of each solid compound present in the mix have been plotted. Apart from char and the intermediate species of cardboard thermal degradation, which are not present at the beginning of combustion, the masses were normalized to their initial values for simplicity. The figure shows clear fronts for the drying and for the devolatilization processes, PE being last to devolatilize. The intermediate species is formed as the front passes and is rapidly converted into char and VM. Very close to the surface - and at this location only-char is oxidized due to the high temperature and the presence of $\mathrm{O}_{2}$. This is in good agreement with the experiment. Indeed, a very thin (not measurable) gray ash layer at the surface of the brick was observed, the color of which was black during the devolatilization process.

The mass fraction profiles for all the gas species considered in the model, at this time $t=1000 \mathrm{~s}$, are reported in Figure 13. VM is the dominant species, with a peak value at the location of the devolatilization front. Water vapor is also present and has diffused with VM to the bottom of the brick. $\mathrm{O}_{2}$ is present only close to the surface, and $\mathrm{CO}$ and $\mathrm{CO}_{2}$ are not present.

An analysis of the situation in terms of fronts during the char oxidation phase can be provided by examination of Figure 14. This figure represents the porosity profile through the sample established at time $t=5000 \mathrm{~s}$. Again, two regions are clearly observed, one close to the bottom where the porosity is that of the char, 0.94 , and the other close to the surface where the porosity is 0.98 , corresponding to the ash porosity. In between these two regions, a char oxidation front is seen. Its thickness is $25 \mathrm{~mm}$. The change in the porosity induced by this reaction is small but, regarding the high reaction heat for this process, the reaction cannot be neglected. Indeed, the char represents approximately $15 \%$ of the initial mass, and, consequently, about the same proportion of the total energy release for the full brick combustion. During this front propagation, the temperature inside the brick is uniform, with values ranging from $714^{\circ} \mathrm{C}$ at the surface to $718^{\circ} \mathrm{C}$ at the bottom. 


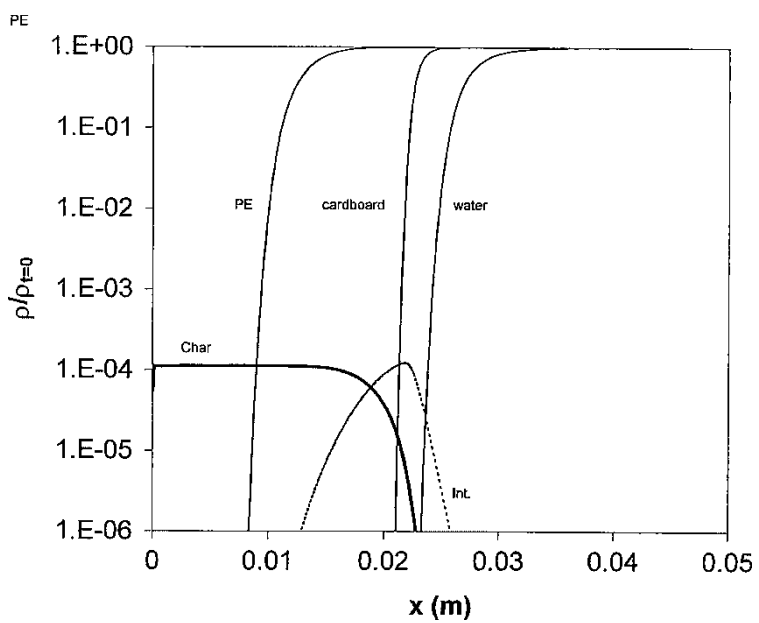

Figure 12. Solid mass concentrations at $t=1000 \mathrm{~s}$ (devolatilization phase); the values for the char and for the intermediate species of cardboard devolatilization could not be normalized to the initial density.

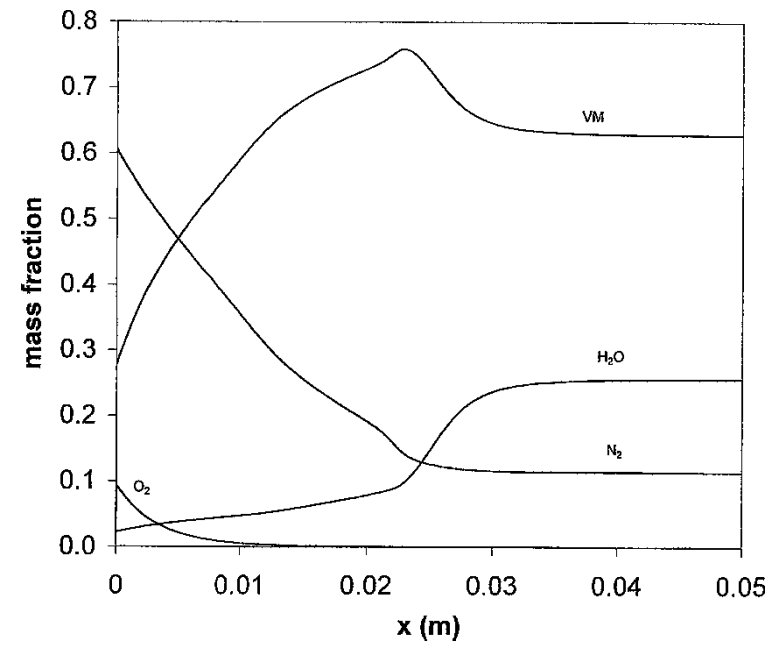

Figure 13. Gas-phase mass fraction fields at $t=1000 \mathrm{~s}$ (devolatilization phase); $Y_{\mathrm{CO}} \approx 0 ; Y_{\mathrm{CO} 2} \approx 0$.

In Figure 15, the mass fraction profiles for all the gas components, during the char oxidation phase, are plotted, at time $t=5000 \mathrm{~s}$. The $\mathrm{O}_{2}$ fraction at the surface is about 0.18 , which is smaller than the value in air (0.23). This indicates a little limitation of the combustion by oxygen transfer at the surface of the brick. Oxygen diminishes as $x$ increases and falls to less than 0.01 at $x=30 \mathrm{~mm}$. Since the temperature inside the brick is uniform at this time, this $\mathrm{O}_{2}$ fraction profile is the explanation for the presence of a char oxidation front. As already discussed, $\mathrm{O}_{2}$ transfer is the limiting mechanism.

The model predicts the formation of $\mathrm{CO}$ in much larger mass fractions than $\mathrm{CO}_{2}$. These two components are found at the brick bottom, where they have diffused. The $\mathrm{CO}$ fraction is high at the sample surface, at approximately 0.08 . This might explain the presence of the thin blue flame 


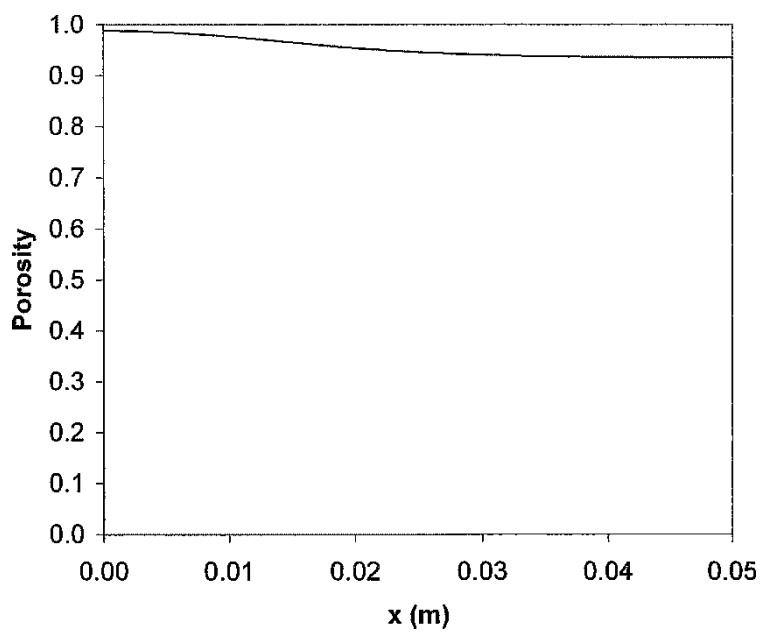

Figure 14. Porosity fields at $t=5000 \mathrm{~s}$ (char oxidation phase).

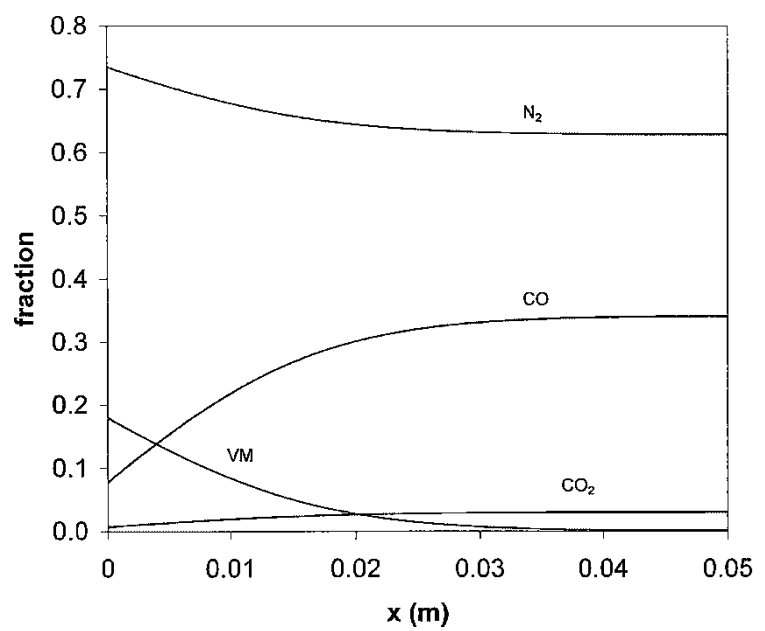

Figure 15. Gas-phase mass fraction fields at $t=5000 \mathrm{~s}$ (char oxidation phase); $Y_{M V} \approx 0 ; Y_{\mathrm{H}_{2} \mathrm{O}} \approx 0$.

'floating' at the surface of the sample during the char oxidation phase, as already discussed when presenting the velocity profiles. Since one mole of oxygen forms two moles of carbon monoxide, a gas flow is induced towards the surface of the sample. During this phase, the value of the velocity at the surface is between $-0.5 \mathrm{~mm} \mathrm{~s}^{-1}$ and $-1 \mathrm{~mm} \mathrm{~s}^{-1}$ (Figure 9).

The model predicts the propagation of two distinct and thick fronts, one for the devolatilization process and the other for the char oxidation reaction. Some evidence of this could also be established during the experimental analysis. Indeed, by stopping an experiment during the devolatilization phase, quenching it in a gas-tight box, and cutting the sample following a vertical section, it was possible to observe different regions inside the sample [1]. Close to the surface, a black char is present under a very thin ash layer. Close to the bottom, the material has kept its initial color. Between the two regions, a mix of brown (original color) cardboard, dark brown cardboard, black 
char and melted PE is observed. Observing the char oxidation front is much more delicate since it is not possible to evaluate the degree of conversion of char into ash by simple observation. Nevertheless, by stopping an experiment during the char oxidation phase, it was possible to observe a gray/white ash layer more than $1 \mathrm{~cm}$ thick at the surface of the sample, whereas the bottom was a black and mechanically strong char. The observation of these two distinct fronts is a new result. Indeed, in classical combustion processes, such as grate furnaces where air is blown through the medium, the two fronts are propagating side by side. The oxidation region of the front is found upstream with respect to the air supply, and the heat that is generated by this reaction is supplied downstream to the devolatilization region of the front. In our case, the devolatilization front prevents oxygen diffusion inside the medium, thus inhibiting char oxidation.

\section{CONCLUSION}

A 1D model describing combustion of a porous medium made of cardboard and PE has been developed and successfully compared with experimental results previously carried on a cone calorimeter, over a large range of initial sample density and composition.

The heat transfer, mass transfer and chemical reaction kinetics phenomena were described, without $a$ priori selecting a controlling mechanism and neglecting the others. The main assumptions were to consider the medium as a continuum, assuming local thermal and chemical equilibrium, and assuming that gas-phase oxidation did not occur inside the porous medium. The present results tend to validate this formulation for such a combustion problem, characterized by the absence of forced air flow through the medium.

The solid properties required in the balance equations were determined by specific experiments, apart from the tortuosity of the medium and the char residue thermal conductivity that are very difficult to measure. It was nevertheless possible to obtain estimates of these two parameters by fitting the predictions of the model with the set of experimental results.

The model allowed us to perform a precise and detailed analysis of the combustion process under consideration, which is very specific as compared with smoldering or flaming propagation in classical beds through which air is blown. At first, a devolatilization front takes place, for which the water vapor and VM production drives away the oxygen. The front thickness is as high as $20 \mathrm{~mm}$ for a sample at $500 \mathrm{~kg} \mathrm{~m}^{-3}$ initial density. During this phase, the total mass loss rate of the sample is about $6.2 \times 10^{-3} \mathrm{~kg} \mathrm{~s}^{-1} \mathrm{~m}^{-2}$. The propagation of this front is not self-sustained, since only endothermic chemical reactions are involved.

Once this front has crossed the entire sample, oxygen can diffuse inside the sample body and a char oxidation front starts at the surface of the sample and propagates through the medium. The thickness of this front is about $25 \mathrm{~mm}$. The total mass loss rate during this phase is approximately 10 times smaller than during the devolatilization phase. Several observations made on samples for which the combustion process was stopped during the devolatilization phase or during the char oxidation phase support these conclusions. The limiting mechanisms are heat diffusion through the devolatilized layers during the devolatilization phase and oxygen diffusion through the ash layers during the char oxidation phase.

For the considered sample permeability, the overpressure inside the medium remains very small so that a treatment with approximate constant values for the permeability of the medium and for the gas viscosity is appropriate. Radiation heat transfer was treated in a very simple manner in this work. Given the high values reached by the medium porosity and the high temperature values, it 
would seem that a good description of this heat transfer mechanism would be a major improvement for such models. Similarly, a better description of the boundary condition at the surface facing the cone would improve the accuracy of the model.

The good agreement between model predictions and experiments validates the model, and it is believed that it can be used with some confidence to develop new substitution fuels made from biomass and plastic materials. It can also be used for evaluating the impact on the combustion process of boundary condition changes, for instance the surface radiative flux and the atmosphere oxygen content.

\section{NOMENCLATURE}

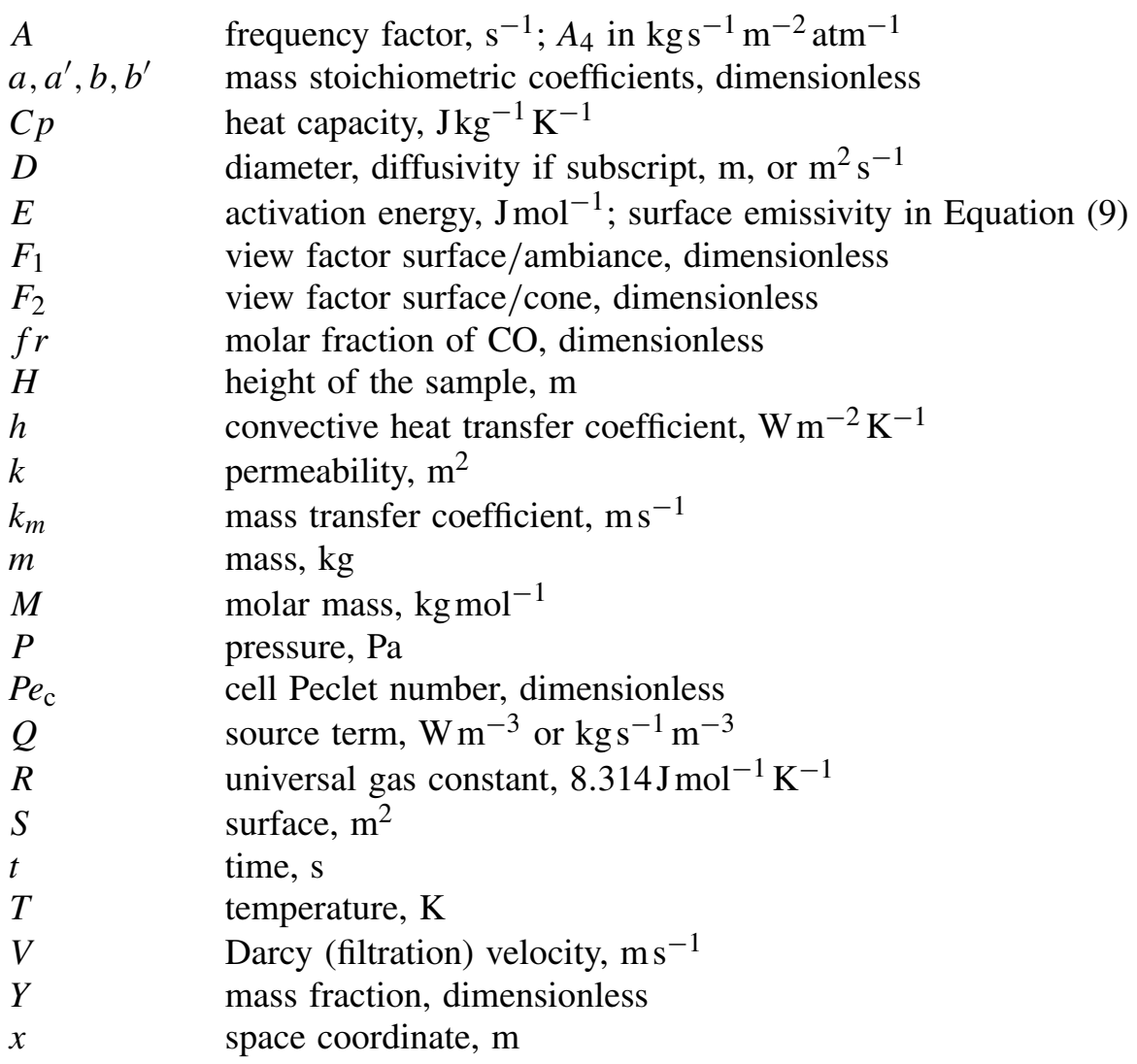

Greek letters

$\begin{array}{ll}\lambda & \text { thermal conductivity, } \mathrm{W} \mathrm{m}^{-1} \mathrm{~K}^{-1} \\ \varepsilon & \text { porosity } \\ \sigma & \text { Stephan-Boltzman constant, } \mathrm{W} \mathrm{m}^{-2} \mathrm{~K}^{-4} \\ \rho & \text { density, } \mathrm{kg} \mathrm{m}^{-3} \\ \mu & \text { dynamic viscosity, } \mathrm{kg} \mathrm{m}^{-1} \mathrm{~s}^{-1} \\ \Delta h & \text { reaction heat, } \mathrm{Jkg}^{-1}\end{array}$




$\begin{array}{ll}\text { Subscripts } \\ \text { amb } & \text { ambiance } \\ \text { ash } & \text { ash } \\ \text { B } & \text { bulk } \\ \text { C } & \text { cardboard } \\ c & \text { heat } \\ \text { Ch } & \text { char } \\ \text { Cone } & \text { heated cone } \\ \text { eff } & \text { effective } \\ \text { g } & \text { gas } \\ \text { intr } & \text { intrinsic, or of pure solid } \\ m & \text { mass } \\ \text { paral } & \text { parallel } \\ \text { PE } & \text { polyethylene } \\ s & \text { solid } \\ \text { ser } & \text { serial } \\ \text { spec } & \text { specific } \\ \text { surf } & \text { surface of the sample } \\ w & \text { water } \\ \text { Superscripts } \\ j & \text { gas species } \\ k & \text { solid species }\end{array}$

\section{REFERENCES}

1. Salvador S, Quintard M, David C. Combustion of a substitution fuel made of cardboard and polyethylene: influence of the mix characteristics-experimental approach. Fuel 2004; 83:451-462.

2. Schult DA, Matkowsky BJ, Volpert VA, Fernandez-Pello AC. Forced forward smolder combustion. Combustion and Flame 1996; 104:1-26.

3. Dosanjh SS, Pagni PJ, Fernandez-Pello AC. Forced cocurrent smoldering combustion. Combustion and Flame 1987; 68:131-142.

4. Horttanainen M. Propagation of the ignition front against air flow in packed beds of wood particles. Ph.D. Thesis, Lappeenrata University of Technology, Finland, November 2001.

5. Fatehi M, Kaviany M. Adiabatic reverse combustion in a packed bed. Combustion and Flame 1994; 99(1):1-17.

6. Fatehi M, Kaviany M. Role of gas-phase reaction and gas-solid thermal nonequilibrium in reverse combustion. International Journal of Heat and Mass Transfer 1997; 40:2607-2620.

7. Janssens M. Piloted ignition of wood: a review. Fire and Materials 1991; 15:151-167.

8. Zhou X, Torero JL, Goudeau JC, Bregeon B. On the propagation of a reaction front through a porous fuel in the presence of an opposed forced flow: application to mixtures characteristic of municipal waste. Combustion Science and Technology 1995; 110-111:123-146.

9. Yang YB, Lim CN, Goodfellow J, Sharifi VN, Swithenbank J. A diffusion model for particle mixing in a packed bed of burning solids. Fuel 2005; 8:213-225.

10. Goh YR, Yang YB, Zakaria R, Siddall RG, Nasserzadeh V, Swithenbank J. Development of an incinerator bed model for municipal solid waste incineration. Combustion Science and Technology 2001; 162:37-58.

11. Akkutulu IY, Yortsos YC. The dynamics of combustion fronts in porous media. Society of Petroleum Engineers Annual Technical Conference and Exhibition, Dallas, TX, 1-4 October 2000; SPE 63225.

12. Aldushin AP, Matkowsky BJ. Instabilities, fingering, the Saffman-Taylor problem in filtration combustion. Combustion Science and Technology 1998; 133(4-6):293-341. 
13. Debenest G, Mourzenko VV, Thovert JF. Smouldering in fixed beds of oil shale grains-A three-dimensional microscale numerical model. Combustion Theory and Modelling 2005; 9:113-135.

14. Yang YB, Goh YR, Zakaria R, Nasserzadeh V, Swithenbank J. Mathematical modelling of MSW incineration on a travelling grid. Waste Management 2002; 22:369-380.

15. Schult DA, Matkowsky BJ, Volpert VA, Fernandez-Pello AC. Forced forward smolder combustion. Combustion and Flame 1996; 104:1-26.

16. Schult DA, Bayliss A, Matkowsky BJ. Traveling waves in natural counterflow filtration combustion and their stability. SIAM Journal on Applied Mathematics 1998; 58(3):806-852.

17. Ohlemiller TJ. Modeling of smouldering combustion propagation. Progress in Energy and Combustion Science 1985; 11:277-310.

18. Kaviany M. Principles of Heat Transfer in Porous Media. Springer: New York, 1996.

19. Kaviany M, Oliveira A. Length scales and innovative use of nonequilibria in porous media combustion. Symposium on Energy Engineering in the 21st Century, Cheng P (ed.). Begell House: New York, 2000; 32-52.

20. Oliveira AAM, Kaviany M. Nonequilibrium in the transport of heat and reactants in combustion in porous media. Progress in Energy and Combustion Science 2001; 27:523-545.

21. Puiroux N, Prat M, Quintard M. Non-equilibrium theories or the macroscale heat transfer: ablative composite layers systems. International Journal of Thermal Sciences 2004; 43:541-554.

22. Quintard M, Whitaker S. One- and two-equation models for transient diffusion processes in two-phase systems. Academic Press: New York, 1993; 369-464.

23. Quintard M, Whitaker S. Local thermal equilibrium for transient heat conduction: theory and comparison with numerical experiments. International Journal of Heat and Mass Transfer 1995; 38:2779-2796.

24. Quintard M, Kaviany M, Whitaker S. Two-medium treatment of heat transfer in porous media: numerical results for effective properties. Advances in Water Resources 1997; 20:77-94.

25. David C, Salvador S, Dirion J-L, Quintard M. Determination of a reaction scheme for cardboard thermal degradation using thermal gravimetric analysis. Journal of Analytical and Applied Pyrolysis 2003; 67/2:307-323.

26. Taylor R, Krishna R. Multicomponent Mass Transfer. Wiley: New York, 1993.

27. Staggs JEJ, Whiteley RH. Modelling the combustion of solid-phase fuels in cone calorimeter experiments. Fire and Materials 1999; 23:63-69.

28. Babrauskas V. Development of the cone calorimeter-a bench scale heat release rate apparatus based on oxygen consumption. Fire and Materials 1984; 8-2:81-95.

29. Wiener O. Die Theorie des Mischkörpers für das Feld des stationaären Störmung. Erste Abhandlung die Mittelswertsätze für Kraft, Polarization und Energie. Abhandlungen der Mathematisch Physischen Klasse der Königlischen-Sachsischen Gesellschaft der Wissenschaften 1912; 32:509-604.

30. Reid RC, Poling BE, Prausnitz JM. The Properties of Gases and Liquids (4th edn). McGraw-Hill: New York, 1987.

31. Ladevie B, Batsale J-C, Fudym O. A new simple device to estimate thermophysical properties of super insulating materials. International Communications in Heat and Mass Transfer 2000; 27(4):473-484.

32. Salvador S, Commandre J-M, Stanmore B. Reaction rates for the oxidation of highly sulphurised petroleum cokes: the influence of thermogravimetric conditions and some coke properties. Fuel 2003; 82:715-720.

33. Arthur JR. Reactions between carbon and oxygen. Transactions of the Faraday Society 1951; 47:164-178.

34. Freire F, Figueuredo A, Ferrao P. Thermal analysis and drying kinetics of olive bagasse. Drying Technology 1999; 17(4-5):895-907.

35. Madhava M, Rao PS, Goswani T. Drying kinetics of Paddy using thermogravimetric analysis. Drying Technology 2001; 19(6):1201-1210.

36. Barry DA, Bajracharya K, Miller CT. Alternative split-operator approach for solving chemical reaction/ groundwater transport models. Advances in Water Resources 1996; 19:261-275.

37. Class H, Helmig R, Bastian P. Numerical simulation of non-isothermal multiphase multicomponent processes in porous media: 1. An efficient solution technique. Advances in Water Resources 2002; 25:533-550.

38. Carrayrou J, Mose R, Behra P. Modélisation du transport réactif en milieu poreux: schéma itératif associé à une combinaison d'éléments finis discontinus et mixtes-hybrides: modelling reactive transport in porous media: iterative scheme and combination of discontinuous and mixed-hybrid finite elements. Comptes Rendus Mécanique 2003; 331:211-216.

39. Quintard M. Diffusion in isotropic and anisotropic porous systems: three-dimensional calculations. Transport in Porous Media 1993; 11(2):187-199.

40. Barry DA, Miller CT, Culligan E, Bajracharya K. Analysis of split operator methods for nonlinear and multispecies groundwater chemical transport models. Mathematics and Computers in Simulation 1997; 43:331-341. 